\title{
Diagnostics for ion beam driven hlgh energy density physics experiments
}

\author{
F. M. Bieniosek, ${ }^{b}$ E. Henestroza, S. Lidia, and P.A. Ni \\ Lawrence Berkeley National Laboratory, Berietey CA 94720 USA \\ and the Heany lon Fusion Science Virual National Laboratory
}

(Presented May 19, 2010; received XXXXX; accepled XXXXX; published online XXXXX)

Intense beams of heavy ions are capable of heating volumetric samples of matter to high energy density.

Experiments are performed on the resulting warm dense matter (WDM) at the NDCX-I ion besm accelerator.

The $0.3 \mathrm{MeV}, 30$-mA K $\mathrm{K}^{+}$bean from NDCX-1 heats foil targets by combined longitudinal and transverse neutralized trift compression of the ion beam. Both the compressed and uncompressed parts of the NDCX-I beam heat targets. The exolic state of matter (WDM) in these experiments requires specialized diagnostic techniques. We have developed a targel chamber and fielded target diagnostics including a fast multi-channel optical pyrometer, optical streak camera, laser Doppler-shift interterometer (VISAR), beam transmission diagnostics, and high-speed gated cameras. We also present plans and opportunities for diagnostic development and a new target chamber for NDCX-II.

\section{INTRODUCTION}

As a lechnique for heating volutherte samples of matter to high energy density, intense beams of heavy ions are capable of delivering prectse and uniform beam energy deposition $d E d x$, in a rebatively large sample size, and with the ability to heal any solid-phose target material. The US heavy ion fusion science program has made significant progress in techntques for heating and diagnosing vam domso matter (WDM) targels [I]. The WDM conditions are axhieved by combined longitudinal and transwerse space-charge neutralized drift compression of the ion beam to provide a hot spot on the target with a beam spot size of aboul I mm or less, and compressed palse lengh about 2 ns. Inifial experiments uso a $0.3 \mathrm{NeV}, 30+\mathrm{mA} \mathrm{K}^{+}$beam foelow the Bragg peak) from the NDCX-I acceleretor to heat foil targels The NDCX-1 beam sontains an uncompressed pulse up to 3 ] 0 He of intensity $20.2 \mathrm{MW} / \mathrm{cm}^{2}$, and a compressed putse of fluence $-10 \mathrm{~mJ} / \mathrm{cm}^{2}$ [2]. Recent improvetonts in the NDCX-[ beamline bave provided increased berm intensily on larget including a new induction bunching module which doubles the wolt-seconds available to provide bunch compression [3]. The temporal profile of the bean current at the target plane is measured with a fast ( 1 ns) Faraday cup and the spattal profile by an $\mathrm{Al}_{2} \mathrm{O}_{3}$ scintillalor and a new/y-developed turgsten foil calorimeter. The range of the beams in solid matter targets is about 0.1 - 1 miction, which can be lengthened by using porous latgets at reduced density. The besm pulse heals solid foil targets (e.g. At, Si, Pt, C) to temperalures sporoaching $0.5 \mathrm{eV}(6000 \mathrm{~K})$.

We have developed a WDM target chamber and fielded a suite of urget diagnostics inchuding a tasl multi-channel optica] pyrometer, optical steak camers, VISAR, and high-speed gated cameras. Initial WDM axperiments heat targets by both the

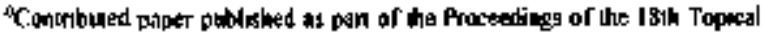

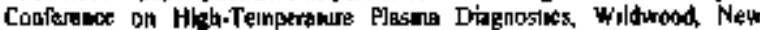
Jersey, May, 2610 This work ans sopported by the Diractor. Ofilce of Seltace. Ofike of Fuswon Enersy Strewtel, of tha U.S. Departmon of Energy

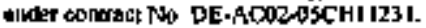

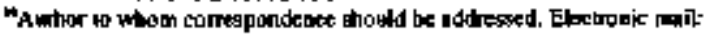

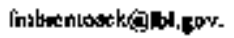

compressed and uncompressed parts of the NDCX-1 beam, and explore measurement of temperature, droplet formation and other target parsmeters. Cominued improvements in bean tming, bunch compression, athd othetr upgrades are expected to yield higher temperature and pressure in the WDM iargets. Future experiments are planned in areas auch as dense electrouegative largets, porous target homogenization and two-phase gas-liquid equation of state. $[4,5]$

\section{TARGET POSITIONER AND DIAGNOSTICS}

The position system has motor drives to provide 6 degrees of fiocdom for remble positionitg of the latgel and optical diagnostics. These inchude 3 axes on the target positioner and 3 axes on the light collection optics toble. The precision larget positioning equipment allows rapid repositioning of the tarist assembly between shots without breaking vacuum, Fig. I shows a plat|hum target after a number of shots were taken on the foil. Up 1040 beem shots have been taken pet day. The target assembly includes a focusing gold cone immediately upstream of the target. [6]

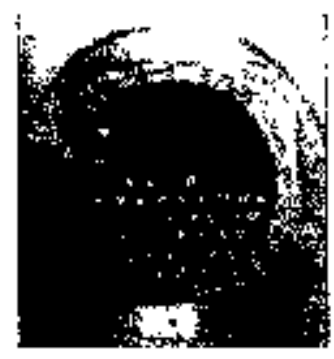

Fig. 1. Target holdet containing a platinum targel boil.

A number of larget diagnostics are inslalled ot utwder development (Fig, 2). The primary optical diagrostics are s fast pyrometer, sheak cameri-spectroneter, and galed optical esmeras. 


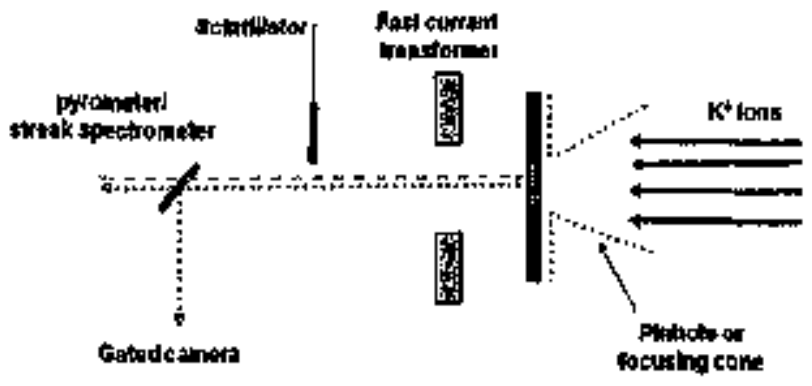

Fig 2, Schematic layout of target diagnostics described in the text.

The light collection system (LCS) optics for pyrouneler and spectrometer diagaostics is based on two achromatic lenses (reiay lens system). It ollows for dorect 1:I imationg of the target surlace onto optical fibets (200-mileron dtamoter) connected to the pyrometa and strisk cemerte. The LCS has a capability for simultaneous usage of the streak-camera-spectrometer and the pyrometer. This is achieved by a custom, setective beam splitter placed aftes the primary collection lens. The beam splitter transmits netre infrared (NIR: 950 to $2000 \mathrm{~nm}$ ) and reflects the Yisible batud (VIS: $\mathbf{4 3 0}$ to $950 \mathrm{~nm}$ ). The NIR fiber is atfached to the pyrometer and the VIS fitor to the strak camera. The LCS also conkains an imaging leg for alignment and target snapshors during the experitment. This imeging les conststs of an indoging fiber guide, macro lens and intensified gated (PIMAX) camera.

A three-channel optical pyrometer probes color teinperatures of the targel at $750 \mathrm{nin}, 1000 \mathrm{~nm}$ and $1500 \mathrm{~mm}$, with $75 \mathrm{ps}$ tempora! resolution. The pyroneter is based on sustom spectraliy selective optical beam splitters and con be uprouded to up to sopen channels. Fach btam splitter toflects a spertral band $150 \mathrm{~nm}$ wide and trantmils the rest. The spectrotly discrimimated light is coupled to an amplified photo-recelver. A Si PIN dode is used as a detector for the visible part of the spectrom and an InGaAs PIN dicte for the near-infrared part. The distinctive fanture of the detectors is that they have a flat gyin curve from DC to $4 \mathrm{GHz}$ with $75 \mathrm{ps}$ rige time. Tho estimated detectable blackbody temperature range is toughly 2000 to $10,000 \mathrm{~K}$,

Contithuous tarect emission from $450 \mathrm{~nm}$ to $850 \mathrm{~nm}$ is provided by a sireak camers combined with a spectrometer. The combination consists of a Horiba jobin Yvon spectromekr

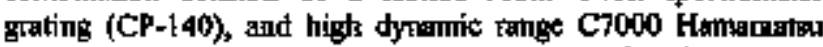
streak camera, which records the spectram as a function of time end wavelength. Fig. 3 shows a bypical target emission spectruth, corrected in lerms of absolute radiation imtensiky (W/cm ${ }^{2} / \mathrm{s}^{2} \mathrm{~m}$ ). Both pyrometer and streak spectrorneter are calibrated absolutely with a NIST traceable tungssten ribbon lamp.

Fast rated imaging of the targets and scintilletors is provided by two Rrinceton Instrutsents PiMAX camecas.

Hydrodynamic expansion velocity of a target's tiee surface is plantred to be measured by a commertially available all. fiber Doppler hif laser interferometer (VTSAR, Velocity Interferometer Syotern for Any Refiector). The installed delay etalon allows for velocity detection with $2 \mathrm{mits}$ precision and 0.5 ns resolution.
Downstieam of the larget is a fast current monitor (Bergoz FCT-016-20:I-VAC). The purpose of the current motitor is to messice beate currem transmitted througb ine targot as a function of time. In a farget thicker than the rangs of the beam, the beam current transwitted should be small even ss the target vaporizes since the bean stopping for solld and vapor target matorial is vety simitar. This is the case if $\mathrm{no}$ droplets form in the target. However when the turgot bumches up into kqnid droplets there is

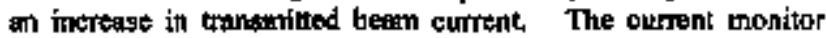
can also be used as a diagnostic of beam trangmission through an opels cone or pinhole in lhe absence of the targel for putposes of colbratlon atod alignment.

A removable $\mathrm{Al}_{2} \mathrm{O}_{3}$ scintiliazor downstream of the target mensures the transmission and scaltering of beam ions downstresm of the target. This measurement provides a diagnostic of the state of the tarpht becanse the transmission and scattering of the beam is sensitive to the smount of matter thea the beam ions pass thtough in the target retion. The scaltered beam profike on the scintiltolor is ingged using a PlMAX camera. One advankage of the scintillator is that it is mainly sessitive to high onergy beam ions, and mucb less sensitive to electrons than the current transformer.

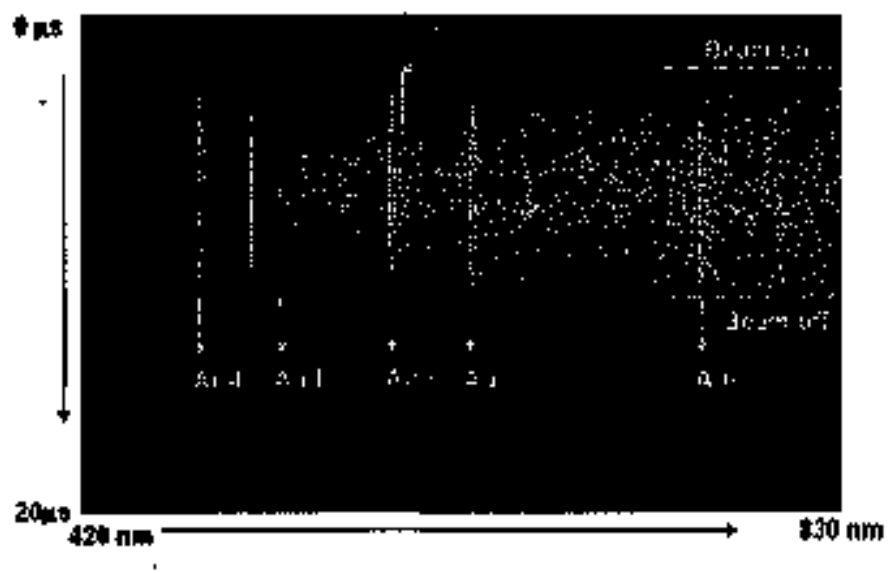

Fig. 3. Emigston of a fu-nm Aul foil as a function of time and wayelength. Beam fum-on and thrn-off times are noted. Beam peumped At I lines (fror NIST bbles) conbined with contimume rafiation emansing forat liquid gold dtopless indicane the presence of both liquid and vapor states.

We late devaloped a 3-eticton tangsten foil calorimeter for absolpte calibration of the incident bean entergy flux using the pyromeler diagnoslics. This calorimeter takes advaniage of the fact that the melting goint of angsten (3422 C) is the highest unong the reftactory metals. The melting point is high enough that the asget peovides a sufficiently intense optical thermal emiasion to the nutri-chantrel end streak pytometer diagnostics while in solid form, thus ensuring that the target remains intact Juring the bean beating pulse during beam inessurement. It thus provides a califtration of the bean flux for comparison with the target scintillator, and is inveluable for toming of the NDCX-I beamline. Since the specitic heat of tungsten is usel! ktrown ap to the meltuth point, the lungeston foil can be utilized as a calorimer. In addition, the meltiats point provides at absolute temperature benctungark for the temperature messurements provided by the optiçal pyrometry diagmostics. Recent theasuremtents indicate that the specific beam energy flux on a 
bare foil target is about 0.25 MW/erre as described in Ref, [7]. Further refimements of the metsurements afe underway.

Other available diagnostica that heve not been implemenled include an electrostritic energy analyzer [\$] for measuring the beam energy and energy fistribution after passtag through the rarget, and several lastis that are available as probes such as a laser backlighter.

\section{EXPERIMENTAL BEAM-TARCET DATA}

NDCX-I beam-target shots have been performed on foil tergets including $\mathrm{AL}, \mathrm{Pt}, \mathrm{C}$, AL, W and Si. Optical data was taken using the gated PIMAX cameras, lhe strtak-camera spectrometer, and the fast optical pyromelet diagnostc. Since the thickness of the Au langet is larger then the range of ions, most of the ions are stopped in the target. The tmoment the spectral lines in Fir. 3 appear is reloted to breaking of the foil into droplets, i.e. $\mathrm{K}^{+}$beam ions now car pass through the void and excite the au atomic vapos downstream of the larget. Oplical imaging of self-emission from the expanding strowe of hoi debris after the target shot indicates the presence of hundreds of hot droplets, suppoiting the characterizalion of the barget as forming tropless early in the beam pulse.

Reconstructed tempersture, $T_{\text {, }}$ is obtainted from non-linęr least square fit of experimental spector, $M(\lambda, t)$ to a radiation model. The model it the Planel formula multiplied by emissivity, $z(\lambda, T)$, which, depending on the situation, can be modeled as having either a linear or square dependence on wavelength [5].

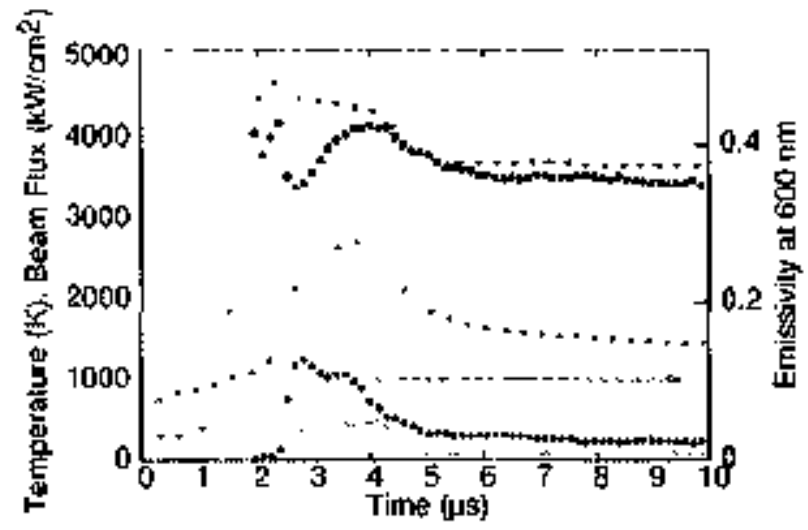

Fis. 4, Reconstructed target kemperature (squares) using a fit to the measured ermission spectrum, brightmess temperanure at 600 $\mathrm{nm}$ (triangles), emissivily al $600 \mathrm{~nm}$ (circles), and reletive time hislory of beam intensity (no marker). The compressed pulse is limed al i $\mu$ s after the hesd of the beam. Alsos showt is the predicted temperature behavior from the equilibrium thodel (inverted triangles) based on the beam curremt pulse shown.

Fig. 4 shows typical streak-spectrometer data for the platinum targel temperature. Note that the measured target temperatore which reaches $>4000 \mathrm{~K}$, reming shighlly lower than the predicted temperature. Rapid changes in larget emissivity account for differences in the brightness tomptrature and reconstrucled temperature.

\section{N, CONCLUSIONS}

Development of techuiques for hasting atd diagnosing tatgets allows bulk heating of WDM targets in the labotatory using ion beam heating. The NDCX-I environment is oonducive to multiple repelitive Iarget experiments for delaikd study of targer behavior under various conditions and using multiple diagnostics. A number of diagnostics have been fielded on NDCX-J. Our experírents are expected to shed light on droplet formation in metal targets under WDM conditions ath on the properties of the subsequent dobis shower [9].

Future plans include torget experiments using the nexl-step facility, NDCX-Il, which is designed to heat lergets at the Brass peak using a 2-3 MeV lifhium ion beam, It is estimated lhat a l$\mu \mathrm{m}$ thick foll will be heated wolumetrically to $I-3 \mathrm{eV}$ kn $<1 \mathrm{~ns}$. NDCX [I is under coustruction and will offer greatly improved beam-target heating capability, with a projected completion date of April 20l2 [10]. A new taiget chamber will ptovide improved diagnostic access and capabilitios. Several diagnoslics are planned to be deweloped, including leser backlighting, laser polarimeter, and $x$-tay backlighting

\section{REFERENCES}

1.B.G. Logan, at al, Heavy im fusions stlence reseurch for hids totergy density physics and fusion applications, IFSA 2007, Joums of Phyrics, Conforence Series 112 (2008) 032029.

2.P.A. Seldl, et 31 ., Nucl. Intttum, Meth. A 6016 [20009] 75-92.

3.S. M. Lidia at al, Commisaioning risulis of the upgraded neutralizes driti compessaion experinnenl, Proc. 2009 Particlo Acceleratox Conference, Vanconver, Paper TU6PF092.

4.F.M. Bıeniosek, E, Herealroza, M. Leitner, B.O. Logan, R.M. More P.K. Roy, P. Nh, P.A. Seidh, W.L. Wedtron, J.S. Bamath, Nucl. tengirum. Melh A 606 (2009) 146-15l.

5.P.A. Ni, F,M. Bieniosek, M. Leinnt, C. Weber and W.L. Waldrom, Nucl, Instrum, Meth, A, 606, 169.17] (2009)

6.F.M. Bienicsek et al, Leser and Particke Bearns 28, 204-21 4 (2010).

7. S.M. Lidia et al. Final forus ion beam iniensity from Itangalen for calorimerer and sxinliflator in NDCX-I, Proc. 2010 Beam hsirumentation

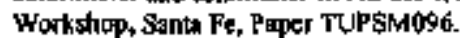

8.F. M. Bientosek, M. Leimer, I-MeV Eledrosdalic Energy Analyzer, Proc. 2007 Patucle Acceleranor Conference, Altuquemque, Papa FRPMSOI8.

9.F.M. Bicntosek ed al., Jon beam driven warys deuse mutler experiments, IFSA 2009. Joumal of Physics, Conferenoe Serress, in press.

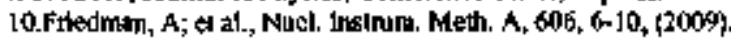

